http://artnodes.uoc.edu

ARTICLE

NODE: «ART MATTERS»

\title{
Diffractive Art Practices: Computation and the Messy Entanglements between Mainstream Contemporary Art, and New Media Art
}

\author{
Helen Pritchard \\ Queen Mary University of London \\ Goldsmiths, University of London
}

\section{Jane Prophet}

School of Creative Media, City University (Hong Kong)

\section{Submission date: April 2015}

Accepted date: May 2015

Published in: June 2015

\begin{abstract}
We engage with Karen Barad's notion of diffraction (2007) to re-evaluate the relations between mainstream contemporary art (MCA) and new media art (NMA) that have been discussed for many years as part of a somewhat contentious debate. Our diffractive reading highlights both large and small but consequential differences between these art practices. We do not smooth over the tensions highlighted in earlier discussions of NMA and MCA. Instead we use Barad's term 'entanglement' to suggest that there are generative 'entanglements', as well as productive differences, between these practices. We extend the debate by considering which differences matter, for whom (artists, gallerists) and how these differences emerge through material-discursive intra-actions. We argue for a new term, diffractive art practices, and suggest that such art practices move beyond the bifurcation of NMA and MCA to partially reconfigure the practices between art, computation and humanities.
\end{abstract}

\section{Keywords}

diffraction, new media art, practice-based research, material feminisms, feminist theory, feminist technoscience

\footnotetext{
* This paper is developed from two papers presented at ISEA2013 on the Media Art, Mediation and Contemporary Art Panel, chaired by Chris Salter with panellists Brogan Bunt, Lucas Ihlein and Janis Jefferies. Helen Pritchard wishes to acknowledge the support of the RCUK Grant EP/G037582/1.

1. We note that terms such as new media art and mainstream contemporary art may be of little relevance anymore, however we use them as signposts for the fields drawing on their previous discussions.
} 


\title{
artnodes
}

http://artnodes.uoc.edu

Diffractive Art Practices: Computation and the Messy Entanglements between...

\section{Prácticas artísticas difractivas: la informática y los complicados enredos \\ entre el arte contemporáneo convencional y el arte de los nuevos medios}

\begin{abstract}
Resumen
Adoptamos la noción de difracción propuesta por Karen Barad (2007) para reevaluar las relaciones entre el arte contemporáneo convencional (ACC) y el arte de los nuevos medios (ANM), sobre las que se ha discutido durante muchos años como parte de un debate algo controvertido. Nuestra lectura difractiva pone de relieve diferencias, grandes y pequeñas pero consecuentes, entre estas prácticas artísticas. No suavizamos las tensiones puestas de relieve en anteriores debates acerca de ANM y MCA, sino que utilizamos el término de Barad, «enredo", para sugerir que existen «enredos» generativos, así como diferencias productivas, entre dichas prácticas. Ampliamos el debate considerando qué diferencias importan, para quién (artistas, galeristas) y cómo dichas diferencias emergen a través de intra-acciones materiales y discursivas. Propugnamos un nuevo término, "prácticas artísticas difractivas", y sugerimos que dichas prácticas artísticas van más allá de la bifurcación de ANM y MCA para reconfigurar parcialmente las prácticas entre arte, informática y humanidades.
\end{abstract}

\section{Palabras clave}

difracción, arte de los nuevos medios, investigación basada en la práctica, feminismos materialistas, teoría feminista, tecnociencia feminista

\section{Introduction}

In this paper we engage with Karen Barad's diffractive methodologies (Barad, 2007) to suggest that there are productive and generative differences between practices of art. To re-evaluate the relations between them, we propose to read the fields of mainstream contemporary art (MCA) and new media art (NMA) diffractively. Our approach is not to bridge the gap (Cornell and Droitcour, 2013, p. 36). and is distinct from those seeking a rapprochement (Shanken, 2002) between NMA and MCA; therefore, this reading revises the position taken in Prophet's paper The Artist in the Laboratory: Co-operating (T)reasonably (Prophet, 2011). We have confined ourselves here to a discussion of NMA and MCA rather than also addressing Sci-Art due to limitations of space. The diffractive reading we present develops a nuanced account of the intra-actions and deep entanglements of NMA and MCA. By reading the fields through each other, we intend to move beyond the often-quoted (Bishop, 2012) mutually exclusive domains of NMA and MCA, whilst retaining difference, variation and heterogeneity.

\section{Diffractive methodology and optical metaphors}

In this paper we use diffraction (Barad, 2007) as an optical metaphor to talk about art practices. Barad describes diffraction as a physical phenomenon that refers to the ways waves (water, light, sound) combine when they overlap. It points to the process of bending and spreading out that occurs when waves encounter obstructions. A familiar example is "the [visible] diffraction or interference pattern that water waves make when they rush through an opening in a breakwater or when stones are dropped in a pond and the ripples overlap" (Barad, 2007). Barad and Donna Haraway (Haraway, 1992; Gibbs, 1998), suggest that diffractions can be used as a useful counterpoint to the metaphor of reflection in technoscience practice (Barad, 2007) because they do not "place the same elsewhere" (Gibbs, 1998). If we take the example of ripples that appear when stones are dropped into a pond, where dynamic and overlapping ripples change one another's form, we can see that diffractive patterns are always in movement, a movement we are also situated within. We only see the differences of the water and the stones when they are in relation to one another, when the stone is thrown into the water and the ripple appears. By contrast the 'bringing together' implied by the term 'rapprochement' is harmonious and cordial, we wish to avoid any reading of NMA returning to MCA for reassurance or validation. Diffraction reveals the ways materialities emerge as differentiated events, as they come together, in relation to one another, and this includes the materiality of stone, water and the thrower. Whereas the common metaphor of reflection (discussed later) might be to 'look back onto' arts practice, diffractive patterns manifest through reading practices through each other. In the metaphor of diffraction, diffractive patterns describe intra-actions and interferences (which 


\section{artnodes}

http://artnodes.uoc.edu

includes practices) from which different entities (which in this case might refer to art works, art theories, art practices) emerge. Barad uses the example of a physics experiment to show how small details in the experimental setup that are both material and discursive (material-discursive) cause different entities to emerge. We use the term difference as Barad does, to refer to the ways entities materialise as differently constituted, i.e. with different characteristics that are not absolute. By attending to diffractive patterns of difference we focus on what the differences are, how they matter, and for what and for whom, attending to the "relational nature of difference" (Barad, 2007). In this paper we draw attention to the patterns of differences between NMA and MCA and highlight how those differences materialise through practices. Diffraction does not fix the object of study and the perceiving subject (the observer and observed) and they are no longer in opposition. A diffractive engagement allows for artworks to be either NMA or MCA or both simultaneously. In this paper we do not use difference to create clear boundaries between practices, but rather to map the material-arrangements that emerge from these differences, furthermore these differences are not fixed, with some works from MCA having the characteristics of NMA and vice versa as discussed later. The diffractive reading and writing process illuminates differences as they emerge, amplifying how such differences get made, revealing what gets included or excluded through practice, and prompting us to question how those exclusions matter.

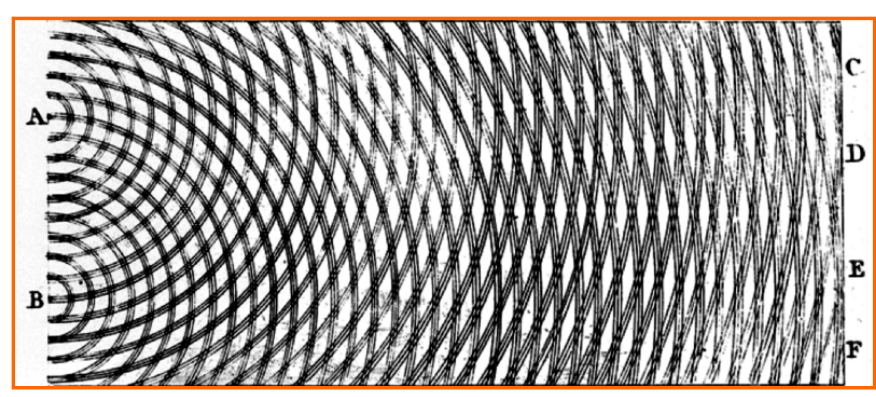

Fig. 1. Thomas Young's sketch of two-slit diffraction, which he presented to the Royal Society in 1803. (Public domain)

\section{Why diffraction?}

Optical metaphors already have a well-established place in thinking about art practice, with reflection or 'reflective practices' (Gibbs, 1998) often used when discussing visual art. Whereas reflection suggests a mirror image, or copy, diffraction invokes "patterns of difference rather than reflecting images" (Haraway, 1997). Over the last two decades the relationship between art and the academy has undergone marked shifts, specifically in the ways that arts practice has been packaged and redefined as practice-based research (Candy
Diffractive Art Practices: Computation and the Messy Entanglements between...

and Edmonds, 2002; Biggs, 2000; Arlander, 2008; Prophet, 2003; MacLeod, 2000; Sullivan, 2010) and has been measured periodically through exercises such as the Research Assessment Exercise or the Research Exercise Framework (REF, 2014). As part of this process, arts practitioners have adopted and adapted methods from other disciplines to articulate our research. This can be seen as a legacy of the widespread belief amongst cultural theorists and producers in the positive results of blurring (another optical metaphor) the boundaries between disciplines (Geertz, 2000). However, recent reevaluations of Clifford Geertz's blurred genres highlight the problems of interpreting blurred genres as an exhortation to smoothing over differences between disciplines (Jay, 2012).

In scrutinising the relationships between MCA and NMA we have found it useful to read through texts of mirroring, blurring and reflecting (Schön, 1991), texts that argue for rapprochement (Shanken, 2002, Prophet, 2011) and those that aim to dissolve perceived differences or separateness between practices of NMA and MCA (Harger, 2012). The underlying premise is that these spheres should be understood as more similar than is commonly held with texts often aiming for what Jay describes as the project of "harmonious reconciliation" (Jay, 2012) between the fields. Diffraction liberates us from this project, allowing us to let go of a focus on similarity, without suggesting that we take up a binary oppositional approach to considering NMA and MCA. Jay (2012) might sympathise with diffraction, as it allows for new types of complexity between or among those spheres as diffractive methodologies build on situated perspectives instead of proposing a separation of subject and object. Diffractive practices recognize the entanglements of subject and object, which Barad describes as "phenomena". Therefore, diffraction as a process-based approach does not fix the object of study or subject in advance and allows for emergence in the research process. We suggest that such material feminist approaches offer a different way of accounting for the new and iterative material arrangements in art.

Barad introduces the optical metaphor of diffraction for re-thinking the relationships between entities and agencies that emerge from scientific practices. In this paper, we borrow from Barad to rethink and theorise about knowledge that emerges from art practices, using Barad's metaphor of diffraction to show that different art practices continuously reconfigure the boundaries between them. Specifically, we look at NMA and MCA practices, suggesting that they are always in the process of being reconfigured, changing what they are and what they can be. The diffraction method allows us to interrupt the tendency to see MCA as a fixed and/or dominant frame of reference against which to read NMA, enabling us to focus our attention on the patterns of interference at the boundaries or overlaps of these practices. Geertz's (2000) proposal of blurred boundaries between disciplines and genres, boundaries that urged social scientists to transgress, included an assertion that particular areas under scrutiny 


\section{artnodes}

http://artnodes.uoc.edu

were "sites of complex interactions" (Jay, 2012). Barad extends this idea with her concept of entanglements. By looking at the rippleeffect, studying the overlaps, we see how particular differences get made through entanglements of MCA and NMA practice. Rather than seeking to define new relations between media art and more genera currents of contemporary art we account for the overlaps between MCA and NMA. These overlaps are always evolving and co-evolving; any boundaries between them are more porous than is commonly articulated yet not inconsequential.

\section{Diffraction and entanglement}

Diffractive readings, across art practices, draw attention to ongoing temporal and spatial entanglements (Barad, 2007). For Barad, entanglement suggests that different entities (materialconfigurations) interweave and entangle in an on-going process of intra-action, resulting in the production of new entities, comprising entangled groupings that, in turn, entangle with others (Barad, 2007) Entanglements are distinct from a blended mass of undifferentiated soup; this is not conflation (Hammarström, 2012). "Entanglement does not mean that what are entangled cannot be differentiated, discussed or remedied, only that the different entangled strands cannot be adequately dealt with in isolation, as if they were unrelated to the others". In his preface to the 2000 edition of Local knowledge, Geertz (2000) writes that his intention is to "preserve the individuality of things and enfold them in larger worlds of sense at the same time". In an intra-active understanding of the enfolding of entangled strands, strands are not self-subsistent entities, but are continuously and coconstitutionally figured in and through their mutual interdependence (Hammarström, 2012). So-called characteristics of the sphere of NMA or of MCA (Coldwell, 2010), for example, materials, processes and physical form(s) become entangled in particular works, causing that work to cross-overfrom, say, NMA to MCA or to become contentious. This notion of crossing over reinforces the polarisation of NMA and MCA and we, therefore, suggest, instead, describing these as part of the interference patterns where NMA and MCA overlap. Artworks made using computation but instantiated in less copyable forms, like, for example, Julian Opie's continuous digital animations on LCD screens are often sold in limited editions. Engaging with material-discursive context of auratic MCA, limiting the number of copies available exploits and counters the copyability of digital media. Therefore it could be said that Julian Opie's work emerges neither because of, nor despite the boundary between MCA and NMA but as part of an interference pattern between MCA and NMA.

Through diffractive reading we pay attention to some of these sorts of entanglements, this attention recognises "we too are part of the world's differential becoming" (Barad, 2007) this is not a case of a "knowing from a distance" (Barad, 2007). Diffractive methodologies
Diffractive Art Practices: Computation and the Messy Entanglements between...

build on situated perspectives (Jones, 2010; Haraway, 1992; Suchman, 2007), however "the point is not simply to put the observer or knower back in the world (as if the world were a container and we merely needed to acknowledge our situatedness in it)" (Barad, 2007); instead they emphasise that instead of there being a separation of subject and object, they are entangled in "phenomena". Objectivity, instead of being about offering an undistorted mirror image of the world, is about accountability and responsibility to the entanglements of which we are a part (Barad, 2007). We have found it useful to "map the effects" (Gibbs, 1998) of these entanglements as part of accounting for art practices that arise in the productive spaces of overlap between these recognized fields. We do not wish to reinstate an oppositional view of the two fields, but instead aim to examine the complex space of differentiated, but not polarised, practices through engaging with specific artworks.

\section{Productive and material differences}

There has been much debate (Teasdale, 2013; Jones, 2013; Jackson, 2012) about Claire Bishop's idea (2012), previously articulated by Christina Albu (2011), that NMA and MCA are (still) mutually exclusive. While Bishop threw her "mind grenade into the contemporary art milieu" (Lichty, 2013), Albu's assertion that "[n]ew media practices continue to remain in a separate sphere" was part of a discussion about potential hybridity between MCA and NMA. Many from NMA have applauded Bishop for spurring on the debate, while simultaneously voicing reservations about her article. Bishop decried artists for not "confront[ing] the question of what it means to think, see, and filter affect through the digital" (Bishop, 2012), and we note her assertion that, "the mainstream art world and its response to the digital are the focus of this essay". She was explicitly not addressing NMA and saw it as a separate sphere. By taking this approach, Bishop perpetuated MCA's position as the fixed, dominant frame of reference for NMA. As the debate grew, it expanded beyond simple refuting of Bishop by naming the names of artists that were involved in critical engagement with digital technologies and began to draw out the critical differences between MCA and NMA. This included discussion of the specific material arrangements of institutions including their histories, policies and funding as well as the form of their venues and events. However, the discussion largely adhered to the widely accepted practice of reading one text or set of ideas against another, again with MCA as the dominant frame of reference. Reading the same debate diffractively reveals, to an extent, what the discursive differences of MCA are and how they matter. This is especially clear in a re-reading of discussions of material characteristics of MCA that are caricatured in the debate, described as white walls, limited editions, wall-hung works, hand made, easily conservable, movable. NMA is also summarised through a set of physical and conceptual 


\section{artnodes}

http://artnodes.uoc.edu

characteristics authors note that interaction, code, screens, browsers, technologies with built-in obsolescence, shifting technical formats, projectors, specialist technical support, limitless copying, machine made, characterise the field. One of the differences discussed was digital artworks' lack of "the comfort of materiality" (Stallabrass, 2003) whereby many immaterial new media artefacts are copyable where "no one copy is better than any other, which may appear in many places at once, which may run out of the control of artists and curators and which are given as a gift. To the extent that online art is associated with the culture of Web 2.0 and the 'wealth of networks', it appears not merely dissociated from the mainstream market for contemporary art but dangerous to it" (Stallabrass, 2003).

Precisely which differences between NMA and MCA matter? In addition to those described above, a number of authors have pointed to the significance of NMA's attention to the digital, interaction, complexity (Galanter, 2007), databases (Paul, 2014), code (Cox and Krysa, 2005) and MCA's different focus on the material object (Paul, 2007), participation (Paul, 2007; Teasdale, 2013). These differences matter for artists, their non-artist collaborators, collectors, dealers, gallerists and public funding bodies (Bishop, 2012). Differences matter in relation to issues (such as, but not limited to) built-in obsolescence and its impact on conservation and stability; the on-going value of auratic art and rarity values in the art market; the lower value assigned to art works that are copiable. The relationship between the moment in time when it is created, and the moment it is viewed also matters to the way a work of art (in whatever media) is received and the shifting contemporaneous meanings made of it (Baxandall, 1998). Just as the material-discourses around MCA change over time, so do those in NMA, for example, in 1969, the exhibition, Cybernetic serendipity (Reichardt, 1969), included prints and objects, but when NMA shifted focus to the virtual and interactive, physical objects and their conceptual concerns almost disappeared from the NMA exhibition circuit. Due to the histories and funding of NMA and its venues and festivals, works disseminated via NMA have tended to foreground computation and new technological arrangements, leaving artists open to the accusation that their works are technologically determined and not engaged enough with material-discourses of technology that include the political, aesthetical and ethical. Understanding the material constitutions of NMA and MCA helps us better understand their differences. In his response to Bishop, Teasdale notes, "a small but telling shift has occurred" and some artists have crossed-overfrom NMA to MCA, "because the work they make is physically - as well as virtually - based" (Albu, 2011). The importance of materiality is addressed by Bishop where she draws attention to the relationship between old media and its obsolescence. If one of the problems (Bishop, 2012) with NMA is its lack of material and its reproducibility, then there is a concurrent value to MCA works made with materials and technologies that are scarce, they become more precious and have greater value in an object-driven art market.
Diffractive Art Practices: Computation and the Messy Entanglements between...

By considering the specific qualities of the materials that constitute the objects, tools and forms of exhibitions, we suggest materiality changes the fields of MCA and NMA.

Although, as discussed, the boundaries of NMA and MCA are continuously emerging, being reformed, the prevalent materialdiscursive context for curators, artists and institutions that selfidentify as being in NMA or MCA are surprisingly fixed, including and excluding particular materials and concepts. Paul notes "[t]he term new media has been used throughout the twentieth century for media that were emerging at any given time" and draws attention to the useful openness of this shifting definition of what new media is. We suggest that, concurrently, this fixation on the newled to a whole plethora of practices being excluded from debates about NMA. For example, until recently, specifically since the rise of maker and DIY culture, NMA debates have largely excluded practices that focus on objects such as digital photography, print-based works, craft, digital artworks or object-based installations that, while they may engage with technology, do not privilege computation. For instance, until very recently, NMA accommodated ALife and generative art, but it did not go so far as to embrace material representations that came out of systems and generative thinking, such as paintings made by machines (such as John F. Simon Junior, Harold Cohen/AARON).

However, some artists sought to create new entanglements and new connections, leading to practices emerging 'between' the fields of NMA and MCA that engage with what is excluded from both fields. While such works have been described as in the so-called divide between the fields of NMA and MCA (Shanken, 2002; Bishop, 2012), we suggest positioning these works differently, specifically as part of an interference pattern generated where ripples from both MCA and NMA converge. What is important for us in doing this is that interference suggests connection, exchange, collision and a degree of identification between forces whereas between fields implies a gap, a lost space, a lack of communication. Artists working through diffraction often deliberately make works that do not conform to the characteristics of NMA or MCA. As Prophet observed (2011), "The productive differences of positioning oneself outside of mainstream contemporary art has its 'upsides'.

To answer Claire Bishop's rhetorical question, "how many [artists] really confront the question of what it means to think, see and filter affect through the digital?" (Bishop, 2012), we argue here that artists' engagement with computation in NMA and MCA (and beyond) has significantly changed both fields, in both their exclusions and inclusions. Furthermore, these works engage with the material discourse, the role, impact and function of computation. For example, processes inherent to many computation-based artworks deny the promise of a stable object, requested by MCA. The engagement with the instability has formed a context for many works that inhabit the boundary zones of MCA and NMA. Indeed, the force of computational processes themselves can be seen as 


\section{artnodes}

http://artnodes.uoc.edu

forming ripples between NMA and MCA. For example, the work of artists Joan Heemskerk and Dirk Paesmans (JODI) in which the execution of source code in OSS/**** (1999) results in a takeover of the host computer. OSS? ${ }^{\star * *}$ is an artwork fuelled by MCA's anxieties and affinities to stability. During exhibitions OSS/**** was not presented in the gallery and instead visitors were invited to take home a CD-ROM, thereby removing the artwork from the exhibition space. The $0 S S{ }^{* * * *}$ programs designed to be run on the visitor's personal computer explore the different physical elements of the 1990s personal computers - the screen, the mouse and the keyboard. The work was executed through the installation of four

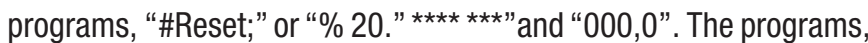
drawing on users' data, transform the computer screen, making it unusable and in some instances irreparable. The lack of a static structure is inherent to the works' materiality. OSS $/{ }^{* * * *}$ comes into being dynamically, each time it is activated the outcome is different, rather than existing as a fixed entity. Works such as $0 S^{* * * * *}$ are always subject to interference from their own processes and utilise this instability deliberately. We suggest that the deliberate foregrounding of instability in $0 S S^{* * * *}$ is in itself an account of the dynamism of [art] practices and a recognition that practices "do not exist as static structures, nor do they merely unfold or evolve in space and time" (Barad, 2007).

While $0 S S{ }^{* * * *}$ attends to the material qualities of instability through the development of bespoke software of executed programs and the physical interfaces of mouse, screen and keyboard, LoVid draws attention to the entanglement of software and hardware in LoVid 486 Shorts, a video installation in which 486 short clips of a circuit short are screened. To make the work, LoVid opened an archaic 486 computer and wired a short circuit onto the hardware of the video card. As "[c]onnections were made on the circuit board of the video card, using wire to produce short videos. Recordings made from these shorts were then edited into 486 Shorts short clips, each corresponding to one of the physical shorts." (Hinkis and Lapidus, 2006). LoVid 486 Shorts makes visible the intra-active entanglement of hardware and software and the ways in which they mutually constitute each other, rather than existing as separate entities (software running on an unaffected hardware). Running code in LoVid 486 Shorts reconfigures the materiality of the 486 Shorts hardware, producing videos by destroying the computer video card. 486 Shorts visualises a set of interferences between hardware, software and art that brings the materiality of computation to our attention.

John F. Simon Junior's Flip (2014) addresses the material that encapsulates hardware and software, referencing the casing of old media. Flip comprises seven wooden cabinet relief works incorporating LCD screens that display his abstract generative images. The MCA critic Walter Robinson described the Flip works "[s]uggesting MidCentury Moderne, the cabinets are multi-coloured and inscribed with elaborate, laser-cut decorations [...] As someone who came of
Diffractive Art Practices: Computation and the Messy Entanglements between...

age during the Conceptual Art era, my first impulse was that all the additional meanings that Simon had layered onto his 'pure' code were extraneous. 'Everything is code', the artist explained. 'And there are lots and lots of codes'". Despite his apparent MCA focus, for Robinson the computer code running to generate images is unproblematic, not a NMA issue. It is a process that is part of, and dependent on, long running material-discursive contexts from Conceptual Art's older, but still relevant, discourses about the removal of the decorative. However, Robinson also situates Flip in the material-discursive context of the 2008 Whitney Biennial, which Robinson defines as "about décor" Robinson (2008).

These material-discursive contexts of MCA in New York, from the 1960s through to 2008 form ripples when they meet materialdiscursive contexts from NMA. Computation such as the operating system, speed, and the types of screens Simon uses, impact the way the work emerges and makes it inherently unstable, like much NMA.

The works described above are more-than simply linear and time-based. Qualitatively different from works that are said to unfold in time in a predictable manner, they demonstrate how computational processes continuously differentiate over space and time. The code running is a process that is often part of, and dependent on, larger material-discursive contexts (the operating system, speed, etc.) all of which potentially impact the way the code runs and make it inherently unstable. Artists such as JODI, Simon Junior and LoVid treat computation as "always something more than mere matter" (Coole and Frost, 2010). They bring attention to the matter and practice of material, recognizing our on-going intra-actions with computation. These works transform iteratively, in what Barad describes as a space-time mattering where the code's material dynamism is implicated in its production. However, works that engage with the dynamics of code practices, have often been excluded from much MCA. MCA has excluded computation-based works from the MCA cannon precisely because they engage with, perpetuate and depend upon unstable processes (Bosma, 2011) that are seen as being at odds with MCA's preferences for fixed and stable objects, they do not easily fit in "[an art] market that prefers and privileges auratic forms" (Bishop, 2013). While MCA has embraced so-called relational art (Paul, 2007) and video art, the stability of the work remains important. Here it is worth noting that the stability of media is important to the MCA market when applied to materials such as paper and paint as well as the digital or immaterial. By considering the specific qualities of the materials that constitute the objects, tools and forms of exhibitions, we suggest how matter changes the fields of MCA and NMA themselves. Such mattering (Barad, 2007) creates new forms of practice that engage with art and other practices, like science, media, ecology, education to name a few, and we see this, for example, in the emergent space of sci-art, bio-art, software art, mixed methods, post-digital practice, art and environment. 


\section{artnodes}

http://artnodes.uoc.edu

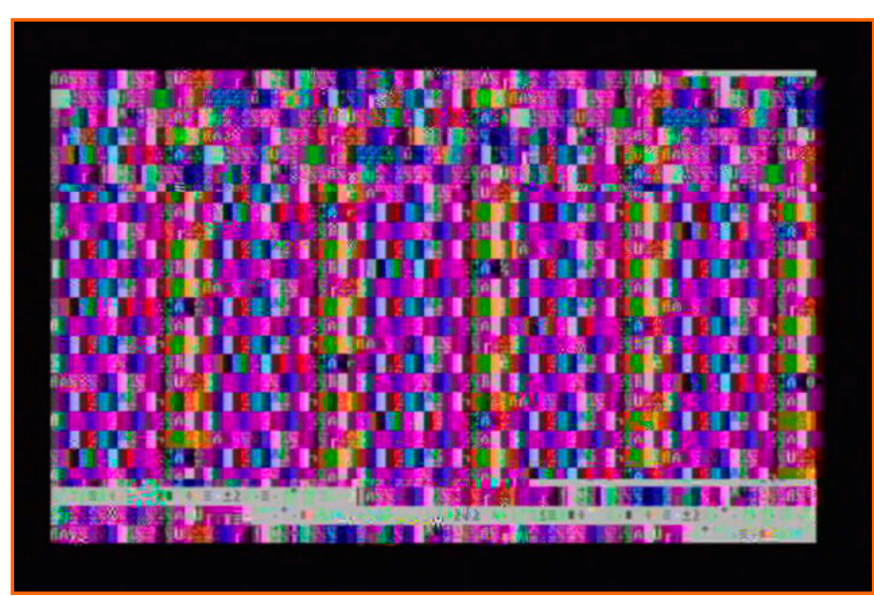

Fig 2. LoVid, 486 Shorts, 2008.

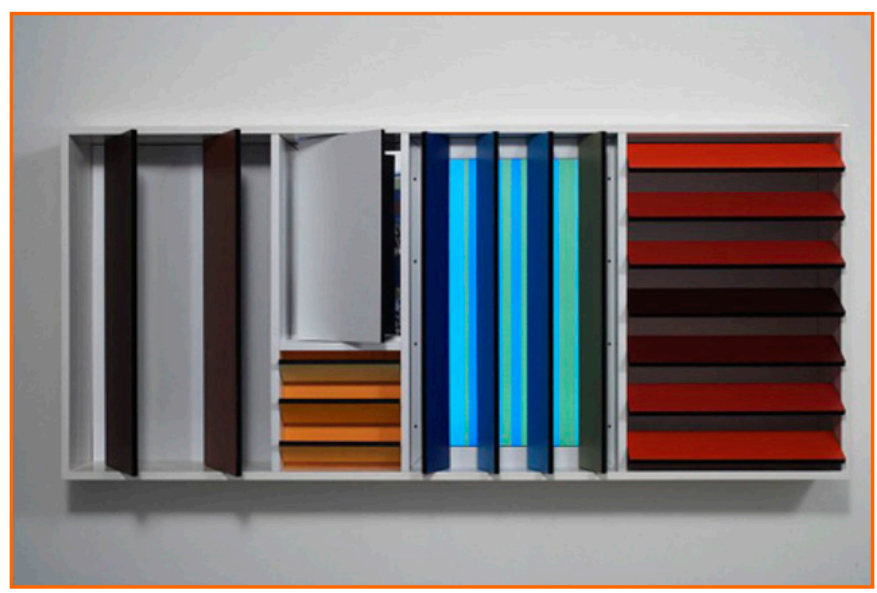

Fig 3. John F. Simon Jr. Flip, 2007, Gering \& López Gallery

\section{How differences get made}

Many NMA works engaging with computation are about practice. As Marcos Novak states, "I would define [NMA] through its engagement with certain technologies that haven't existed before and in terms of how one approaches these technologies. What characterises it is that instead of making the thing, the way a potter makes a pot by direct interaction with the material, there is a degree of indirection. Instead of making the thing you set the motion into process and the process makes the thing" (Jennings, 2000). This emphasis on practice, common to many NMA works, is another reason why it is useful to use Barad's ideas, as in her theorising for diffraction she provides a way to account for practices and processes that materialise objects. Moreover, she emphasises the practices and processes that come before the object (Barad, 2007). In NMA, where many of the artworks are process based, the practice and the process are often conflated with the object. When Bishop wrote that "the digital, by contrast [to
Diffractive Art Practices: Computation and the Messy Entanglements between...

photography and film], is code, inherently alien to human perception" (Bishop, 2013), she was rebuffed by Harger who reminded us that "[code is] certainly not alien to the humans - who are, it should be noted, often artists - that write it." Bishop's argument relies on differentiating code from the artworks it relates to, to the extent that code is presented as being in opposition to, in contrast to the artwork. In the material-discursive context of NMA, code (and computation) are inherent to the art that emerges with them, they are "constitutive elements of material processes" (Gabrys, 2011). By focusing on code, Bishop was considering a specific material that is central to the constitution of many objects, tools and forms of exhibitions in NMA. While we agree with Harger that that code is not alien, we also think that Bishop was onto something with her description. In relation to the materials and processes of film and photography, the particular qualities of computation (one of which is code), are seemingly alien or inhuman, "the humanly un-thinkable" (Barad, 2007).

\section{Conclusion: diffractive practices}

The topologies of NMA and MCA have iteratively changed, have been continually emerging, throughout the twentieth and twenty-first centuries. As a result of matter's dynamism (Barad, 2007), the fields of NMA and MCA have excluded as much as they have included. MCA and NMA works are configurations of entangled relations, entanglements that create temporal, spatial relations with each other and with processes and practices from other disciplines. Bishop (2012) and Stallabrass (2013) have described boundaries between disciplines as less permeable, others have described their practices as relational (Bourriaud, 2002), collaborative, interdisciplinary or transdisciplinary (Prophet and Inverno, 2006; C. Frost, 2012), after new media (Graham and Cook, 2010), or post digital (Gansing, 2013; Andersen et al., 2013). We suggest that material feminisms offer a different way of accounting for the new and iterative material arrangements that have emerged from computation's entanglements with art. Specifically, after Barad (2007), we suggest the term diffractive art practices to understand the "always-already" entangled practices of art, namely the entanglement of material practices and the entanglements of the ways we articulate the practices of art and the practices themselves. These entanglements can be understood as emerging from the patterns of interference that are sometimes revealed through artworks.

\section{Reference}

ALBU, C. (2011). "Five Degrees of Separation between Art and New Media: Art and technology Projects under the Critical lens". Artnodes. no. 11. UOC. 


\section{artnodes}

http://artnodes.uoc.edu

ARLANDER, A. (2008). "Finding Your way Through The Woods". Experiences of Artistic Research. Nordic Theatre Studies, pp. 28-41.

BARAD, K. (2007). Meeting the Universe Halfway: Quantum Physics and the Entanglement of Matter and Meaning. Durham, NC: Duke University Press Books. $<$ http://dx.doi.org/10.1215/9780822388128>

BAXANDALL, M. (1988). Painting and experience in fifteenth century Italy: a primer in the social history of pictorial style. 0xford: 0xford University Press.

BIGGS, M. A. R. (2000) "Editorial: the foundations of practice-based research". In: Working Papers in Art and Design. Hatfield: University of Hertfordshire.

BISHOP, C. (2012). "Digital divide”. Artforum International 51, no. 1, pp. 434-441.

BISHOP, C. (2013). "Technical Difficulties Response." Artforum International 51, no. 5, pp. 38-38.

BOSMA, J. (2011). Nettitudes: Let's Talk Net Art. Nai Publishers.

BOURRIAUD, N. (2002). Relational aesthetics. Dijon: Les presses du reel.

CANDY, L.; EDMONDS, E. (2002). Explorations in art and technology. London: Springer. <http://dx.doi.org/10.1007/978-1-4471-0197$0>$

COLDWELL, P. (2010). Printmaking: a contemporary perspective.: Black Dog. Pub Limited.

COOLE, D. H.; FROST, S. (2010) "Introducing the new materialisms." In: New Materialisms: Ontology, Agency, and Politics. Durham London: Duke University Press, pp. 1-43. <http://dx.doi. org/10.1215/9780822392996-001>

CORNELL, L.; DROITCOUR, B. (2013). "Technical Difficulties". ARTFORUM International, vol. 51, no. 5, p. 36.

COX, G.; KRYSA, J. (2005). "Introduction to the author as (digital) producer". In: Engineering culture:the author as (digital) producer. Ed.: Autonomedia, vol. 2.

FROST, C. (2012) p2pfoundation [Online]. <http://p2pfoundation.net/ World_of_Free_and_Open_Source_Art\#Essays_.26_Interviews> GABRYS, J. (2011). Digital Rubbish:A Natural History of Electronics. Ann Arbor: The University of Michigan Press.

GALANTER, P. (2011). «Shot By Both Sides: Art-Science And the War Between Science And the Humanities.» Artnodes, no. 11. < http:// dx.doi.org/10.3998/dcbooks.9380304.0001.001>

GANSING, K. (2013). Transmediale Festival [Online]. <http://www. transmediale.de/files/2_Curatorial_Statement.pdf >

GEERTZ, C. (2000). Local knowledge: Further essays in interpretive anthropology. Basic books.

GIBBS, G. (1998). Learning by Doing: A guide to teaching and learning methods. Oxford.: Further Education Unit, Oxford Polytechnic.

GRAHAM, B.; COOK, S. (2010). Rethinking Curating: Art after New Media. Leonardo Books, MIT Press, 2010.
Diffractive Art Practices: Computation and the Messy Entanglements between...

HAMMARSTRÖM, M. (2012) “(Mis) understanding Intra-active Entanglement-Comments on René Rosfort's Criticism of Karen Barad's Agential Realism”. Kvinder, Køn og Forskning. No. 4.

HARAWAY, D. J. (1992). "The promises of monsters: a regenerative politics for inappropriate/d others." Cultural studies.

HARAWAY, D. J. (1997). Modest-Witness@ Second-Millennium. FemaleMan-Meets-OncoMouse: Feminism and Technoscience. Psychology Press.

HARDING, S. G. (1991). Whose science? Whose knowledge?: Thinking from women's lives. Cornell University Press.

HARGER, H. (2012) Blog. [Online]. <http://honorharger.wordpress. com/2012/09/02/why-contemporary-art-fails-to-come-to-gripswith-digital-a-response-to-claire-bishop/>

HINKIS, T.; LAPIDUS, K. (2006) Lo Vid [Online]. <http://www.lovid. org/works/486/>

JACKSON, R. (2012) Furtherfield Features [Online]. <http://www. furtherfield.org/features/articles/making-digital-divide-cheapand-nasty>

JAY, M. (2012). "Introduction: Genres of Blur." Common Knowledge. vol. 18, pp. 220-228.<http://dx.doi.org/10.1215/0961754X-1544905>

JENNINGS, P. (2000). "New Media Arts, New Funding Models". Creativity \& Culture.

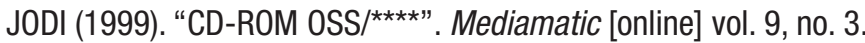
$<\mathrm{http}$ ://www.mediamatic.nl/magazine/9_3/>.

JONES, C. (2013). "Conceptual Blind Spots." Mousse, no. 38.

LICHTY, P. (2013). Furtherfield Features [Online]. <http://www. furtherfield.org/blog/patrick-lichty/disjointed-conversation$\%$ E2\%80\%93-claire-bishop-digital-divide-and-state-newmedia-conte>

MacLEOD, K. (2000). "The functions of the written text in practicebased PhD submissions". Working Papers in Art and Design, no. 1. <http://www.herts.ac.uk/artdes/research/papers/wpades/vol1/ macleod2.html.>

PAUL, C. (2007). "The database as system and cultural form: Anatomies of cultural narratives". In: Victoria VESNA (ed). Database Aesthetics. Minnesota Press.

PROPHET, J. (2003). “Research/Practice/Practice/Research”. CUMIS. Cambridge University.

PROPHET, J.; d'INVERNO, M. (2006). "Transdisciplinary Collaboration in CELL”. In: Paul A. FISHWICK (ed.). Aesthetic Computing. MIT Press, pp. 185-196

PROPHET, J. (2011). "the Artist in the laboratory: co-operating (t) reasonably." Artnodes, no. 11.

REF (2014). Comprehensive information about the Research Excellence Framework. [Online]. <http://www.ref.ac.uk/>

REICHARDT, J. (ed., 1969). Cybernetic serendipity: the computer and the arts. Praeger.

ROBINSON,W. (2008). "Weekend Update." Artnet[Online]. <http://www. artnet.com/magazineus/reviews/robinson/robinson3-10-08.asp> 


\title{
artnodes
}

http://artnodes.uoc.edu

SCHÖN, D. A. (1991). The Reflective Turn: Case Studies In and On Educational Practice. New York: Teachers Press, Columbia University.

SHANKEN, E. A. (2002). "Art in the information age: Technology and conceptual art". Leonardo, vol. 35, no. 4, pp. 433-438. <http:// dx.doi.org/10.1162/002409402760181259>

SIMON, J. F. [Online]. Art Projects by John F. Simon, Jr. <http://www. numeral.com>.

STALLABRASS, J. (2003). Internet art: The online clash of culture and commerce. London: Tate Publishing.
Diffractive Art Practices: Computation and the Messy Entanglements between...

SUCHMAN, L. (2007). Human-machine reconfigurations: Plans and situated actions. Cambridge University Press.

SULLIVAN, G. (2010). Art practice as research: Inquiry in visual arts. Sage.

TEASDALE, P. (2013). "Net Gains: Claire Bishop versus the Internet". Frieze magazine. №. 153.

ULRIK ANDERSEN, Christian; COX, Geoff; PAPADOPOULOS, Georgios (2013). "A peer-reviewed journal about: Post Digital Research". Transmediale. vol. 3, no. 1.

\section{Recommended citation}

PRITCHARD, Helen; PROPHET, Jane (2015). "Diffractive Art Practices: Computation and the Messy Entanglements Between Mainstream Contemporary Art, and New Media Art" In: Pau ALSINA and Ana RODRÍGUEZ GRANELL (cord) "Art Matters". Artnodes. No. 15, pp. 5-14. UOC [Accessed: $\mathrm{dd} / \mathrm{mm} / \mathrm{yy}]$.

$<$ http://journals.uoc.edu/ojs/index.php/artnodes/article/view/n15-pritchard-prophet/n15pritchard-prophet-pdf-en>

$<$ http://dx.doi.org/10.7238/a.v0i15.2594>

This article is - unless indicated otherwise - covered by the Creative Commons Spain Attribution 3.0

(c) licence. You may copy, distribute, transmit and adapt the work, provided you attribute it (authorship,

journal name, publisher) in the manner specified by the author(s) or licensor(s). The full text of the

licence can be consulted here: $\mathrm{http}: / /$ creativecommons.org/licenses/by/3.0/es/deed.en.

\section{CV}

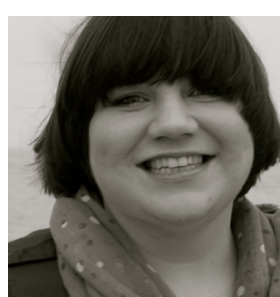

\author{
Helen Pritchard \\ Queen Mary University of London \\ Goldsmiths, University of London \\ h.pritchard@gold.ac.uk \\ http://www.helenpritchard.info/
}

\section{School of Geography \\ Queen Mary \\ University of London}

Helen is an artist and researcher whose work is interdisciplinary and brings together the fields of Computational Aesthetics, Software Studies, Environmental Practice and Material Feminisms. She is a PhD candidate at Queen Mary, University of London and a researcher in the Department of Sociology at Goldsmiths, University of London. 


\section{artnodes}

http://artnodes.uoc.edu

Diffractive Art Practices: Computation and the Messy Entanglements between...

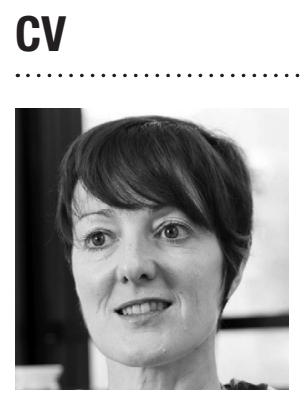

\section{Jane Prophet}

School of Creative Media, City University (Hong Kong)

jprophet@cityu.edu.hk

City University, Hong Kong

School of Creative Media

CityU

Hong Kong

Jane Prophet is a visual artist committed to interdisciplinary collaborative research. She uses a wide range of old and new media in the production of her art. She is Professor in the School of Creative Media at City University, Hong Kong.

\section{$\square$ UOC \\ Universitat Oberta \\ de Catalunya}

